\title{
Ueber eine neue Methode der Caseïn- und Fettbestimmung in der Milch;
}

\section{von Julius Lehmann.}

(Der k. Academie der Wissenschaften zu München vorgelegt in der Sitzung am 7. Juli 1877.)

Ein Jeder, der die bereits sehr zahlreichen, zur Prüfung der Milch vorgeschlagenen Methoden einer mit wissenschaftlicher Schärfe durchgeführten Controle unterworfen hat, ist zu der Erkenntnifs gelangt, dafs von allen denselben nur die quantitative chemische Analyse im Stande ist, über die Qualität der Milch derartig zu entscheiden, dafs dadurch nicht allein den Zwecken der Wissenschaft, sondern auch (und zwar bei streitigen Fällen von Milchfälschungen) den Gerichtsbehörden sichere Anhaltspunkte geboten werden können.

Leider ist jedoch die bisherige Art der Milchanalyse sehr umständlich und zeitraubend und gerade dieser Uebelstand verursacht in physiologischer und sanitätspolizeilicher Hinsicht eine viel geringere Anwendung derselben, als nach beiden Richtungen erforderlich wäre. Denn unbedingt erforderlich wäre eine vermehrte Anwendung, um einestheils die so nöthige Kenntnifs der innerhalb und aufserhalb des thierischen Organismus auf die Zusammensetzung der Milch wirksamen Factoren beträchtlich zu erweitern, anderntheils aber auch der Controle des Milchmarktes denjenigen Grad von Sicherheit zu geben, welchen sie zu ihrer gewissenhaften und erfolgreichen Ausübung bedarf.

Bei den verhältnifsmäfsig wenigen Arbeitskräften, die den meisten physiologischen und sanitätspolizeilichen Instituten zur Verfügung stehen, dürften daher Wissenschaft und Praxis 
auf die Lösung jener wichtigen Aufgaben noch lange Zeit vergeblich zu warten haben. Ganz anders und viel vortheilhafter würde sich diefs gestalten, wenn es gelänge, die Methode der Milchanalyse wesentlich zu vereinfachen, ohne jedoch dadurch der Exactheit der Resultate irgendwie Eintrag zu thun.

Von dieser Ansicht geleitet habe ich mich längere Zeit mit dahin einschlägigen Untersuchungen beschäftigt und werde weiter unten den Beweis liefern, dafs diefs nicht ohne Erfolg geschehen ist.

Ich bin hierbei von einzelnen, von mir angestellten Versuchen über das Verhalten der Milch auf gebrannten porösen Thonplatten ausgegangen. Sie hatten ergeben, dafs von der Milch, welche vermittelst einer Pipette oder eines Spritzglases in einer zusammenhängenden Schicht bis ungefähr zu 2 MM. Stärke langsam auf solche Platten aufgetragen wird, nach Verlauf von ein bis zwei Stunden ein scharf abgegrenzter, consistenter, schwach gelblich gefärbter, fettglänzender Beleg zurückbleibt. Derselbe lärst sich mit einem scharfen Hornspatel von der Platte in der Form feiner durchscheinender Lamellen sehr leicht vollständig abtrennen. Schon nach einigem Stehen an nicht zu feuchter Luft, noch mehr aber beim Trocknen über Schwefelsäure werden dieselben so spröde, dâs sie sich zwischen den Fingern zerbrechen lassen. Unter Einflufs von einigen $30^{\circ} \mathrm{C}$. Wärme schwitzt Fett aus den Lamellen und überzieht deren ganze Oberfläche. Nach dem Auswaschen mit Aether bleibt eine weifse durchscheinende, leicht pulverisirbare Masse zurück. Dieselbe besteht, nachdem sie vom Fett befreit ist, aus aschehaltigem Caseïn und sehr geringen Antheilen von Albumim und Milchzucker.

Vermittelst Thonplatten läfst sich daher das Caseïn und 
Fett von dem Serum der Milch trennen *). Weiter hat sich bei meinen Versuchen über das Verhalten der Milch auf Thonplatten die bemerkenswerthe Thatsache herausgestellt, dafs auf diese Weise das Caseïn sich mit den nämlichen Eigenschaften abscheidet, wie das durch Lab gefällte. Mit Wasser verrieben quillt es zu einer weichen flockigen Masse auf, die beim Filtriren durch Fliefspapier zurückbleibt. Nur mit Kalkwasser geht es wieder in den Zustand über, in welchem es ursprünglich in der Milch enthalten war. Es läuft dann mit dem Wasser durch das Filter und läfst sich mit Essigsäure in Flocken ausfällen. Enthält das Caseïn noch die Fettmengen, mit welchen es auf Thonplatten zurückgeblieben war, dann bildet es mit Kalkwasser verrieben wieder eine der Milch ganz ähnliche Flüssigkeit.

In diesem, sowie in dem mit Lab ausgeschiedenen Caseïn sind gleich grofse Aschenmengen und zwar im Durchschnitt 8,5 pC., während in dem mit Essigsäure gefällten Caseïn nur $1,8 \mathrm{pC}$. Asche enthalten ist. In dem letzteren Caseïn ist deren Hauptbestandtheil Dihydrocalciumphosphat, in den ersteren beiden Caseïnen neutrales Tricalciumphosphat. Ueber die specielle Zusammensetzung dieser Aschen und über deren Einflufs auf die Eigenschaften des einen und anderen Caseïns werde ich später ausführlich berichten.

Die obigen, über das Verhalten der Milch auf Thonplatten gemachten Beobachtungen dürften noch insofern von einigem Interesse sein, als sie die in neuerer Zeit von HoppeSeyler, Soxhlet und Hammarsten ausgesprochene Ansicht, dafs das Caseïn in der Milch nicht in einem gelösten, sondern nur in einem stark aufgequollenen Zustande enthalten sei, bestätigen. Denn wäre das Caseïn gelöst, so

*) Vgl. anch F. W. Zahn's Versuche über die Filtration der Milch durch Thonzellen unter Druck. Archiv für die gesammte Physiologie von Pflüger $\mathbf{2}, 590$. 
mülste es ebenso wie das Albumin mit dem Serum von den Thonplatten aufgesaugt werden. Diefs findet aber nicht statt. Das Caseïn bleibt, wie ich weiter unten bestimmt beweisen werde, selbst auf verhältnifsmäfsig recht porösen Thonplatten vollständig zurück, während das Albumin eingesaugt wird. Man könnte zwar hierbei den Einwurf machen, dafs das Caseïn nicht durch seine in der Milch unlösliche Form, möglicherweise aber durch das Butterfett auf der Oberfläche zurückgehalten werde. Dieser Einwurf wird jedoch schon dadurch hinfällig, dafs dann das Fett in gleicher Weise auf das Albumin einwirken müfste, was jedoch nicht der Fall ist.

Ferner geben die obigen Beobachtungen über das Fett in dem Rückstand auf Thonplatten Veranlassung, die Fettkügelchen in der Milch als frei von einer festen Hïlle anzunehmen, weil schon bei geringer Wärme das Fett aus den Lamellen ausschwitzt und sich mit Aether leicht auswaschen läfst. Würden die Milchkügelchen eine Hülle haben, so könnte eine derartige Erscheinung nicht eintreten; sie müfsten sich dann in dem Thonplattenrückstand gegen Wärme und Aether eben so renitent verhalten, wie sie diefs in der Milch thun. Ich hoffe, durch weitere Untersuchung dieses Thonplattenrückstandes die Natur der Milchkügelchen mit Sicherheit feststellen zu können.

Das ganze Verhalten der Milch auf Thonplatten führte mich nun zu der Ansicht, dafs es wohl möglich sei, darauf eine neue Methode der quantitativen Bestimmung des in der Milch enthaltenen Caseïns und Fettes zu gründen. Das erste Erfordernifs hierzu war die Ausfindigmachung von Thonplatten, deren Poren das Serum, aber nicht die Milchkügelchen und das Caseïn durchlassen und die aufserdem so glatt auf ihrer Oberfläche sind, dafs sich davon der Rückstand mit quantitativer Genauigkeit ablösen läfst. Von diesen Bedingungen mufste vor Allem der Erfolg abhängig sein. 
Die Milchkügelchen haben nach den Untersuchungen verschiedener Forscher einen Durchmesser von 0,001 bis 0,025 Millimeter. Es müssen daher die Poren der Thonplatten so fein sein, dafs sie die kleinsten Milchkügelchen nicht einsaugen können. Trotzdem ich Thonplatten von den verschiedensten Firmen bezogen, habe ich bis jetzt nur von einer dieser Firmen einzelne Platten erhalten, welche den Anforderungen vollständig entsprachen. Mit diesen Platten wurden dann aber auch ganz exacte analytische Resultate erzielt. Damit ist immerhin der Beweis geliefert, dafs es überhaupt möglich ist, Platten von geeigneter Beschaffenheit zu obigem Zwecke herzustellen. Aufserdem werden auch zu poröse Platten nachträglich noch mit einem Ueberzug versehen werden können, welcher ihnen die zweckentsprechende Beschaffenheit ertheilt.

Die Ausführung meiner Methode der Bestimmung des Caseïns und Fettes in der Milch besteht in Folgendem :

Geeignete Thonplatten werden, nachdem sie einige Zeit bis auf oder über $100^{\circ}$ erhitzt und wieder abgekühlt worden waren, bei schräger Haltung auf der glatten Oberfläche mit einem dünnen Strahl Wasser schnell übergossen und auf ein verhältnifsmäfsig weites Glasgefäfs gesetzt, dessen Boden mit einer dünnen Schicht concentrirter Schwefelsäure bedeckt ist. Die zu untersuchende Milch wird dann, nach vorheriger Verdünnung mit genau der gleichen Gewichtsmenge destillirten Wassers, vermittelst eines kleinen Spritzglases vorsichtig und in vollem Zusammenhange auf den mittleren Theil der Platte aufgetragen und, um Verdampfung zu vermeiden, mit einem glattrandigen Glasschälchen bedeckt*).

*) Diese Operationen sind zur vollständigen Absaugung des Serum: unbedingt erforderlich. Theilweise Verdampfung der Milch as freier Luft ist zu vermeiden. 
Zur Bestimmung des Gewichts der zu untersuchenden Milch wird vor und nach ihrem Auftragen das Spritzglas gewogen. Es genügen circa 9 bis $10 \mathrm{Grm}$. verdünnter Milch, um ein ganz sicheres analytisches Resultat zu erhalten. Damit man einen Anhaltspunkt habe, nicht viel mehr oder weniger Milch zu nehmen, habe ich Spritzgläser in Cubikcentimetertheilung mit eingebrannten schwarzen Linien herstellen lassen.

Das Serum von der oben angegebenen Menge verdünnter Milch wird schon nach Verlauf von 1 bis 2 Stunden derartig von der Platte eingesaugt, dafs man den aus Casein und Fett bestehenden Rückstand vermittelst eines von mir zu diesem speciellen $Z_{w e c k}$ angegebenen und hier angefertigten starken, an der unteren Seite gut zugeschärften Hornspatels abnehmen und in ein gewogenes Uhrschälchen bringen kann. Dieser Rückstand wird dann bei $105^{\circ} \mathrm{C}$. im Luftbade getrocknet (was stets nach zwei Stunden vollständig erfolgt ist) und gewogen. Man erhält auf diese Weise die gesammte Menge Casein und Fett als Trockensubstanz. Um darin jene beiden Bestandtheile getrennt zu bestimmen, wird die Trockensubstanz, ohne sie vorher pulverisirt zu haben, vermittelst einer Pincette auf ein gewogenes, bei $105^{\circ}$ getrocknetes Filter gebracht und zuerst mit einer kleinen Menge Aether abgewaschen. Ist diefs geschehen, so bringt man sie in einen kleinen glatten, mit Ausgufs versehenen Glasmörser und pulverisirt sie unter Zusatz einiger Tropfen absoluten Alkohols aufs Feinste, setzt nun Aether zu, spült sie damit auf das Filter und wäscht sie bis zu ihrer vollständigen Befreiung vom Fett aus. Nach Verdampfung des abfiltrirten alkoholhaltigen Aethers bleibt in dem vorher gewogenen Kölbchen das Fett zurück, welches nach genügendem Austrocknen gewogen wird.

Um das Caseïn zu bestimmen, hraucht man nur das 
Filter plus Rückstand wieder bei der oben angegebenen Temperatur so lange auszutrocknen, bis es nicht mehr an Gewicht verliert. Da aber in dem Caseïn noch ziemlich beträchtliche Antheile von Asche enthalten sind, so mufs auch diese speciell bestimmt und in Abrechnung gebracht werden. Das auf angegebene Weise erhaltene Casein ergiebt bei der Verbrennung mit Natronkalk, auf aschefreie Substanz berechnet, im Mittel 15,57 pC. Stickstoff. Bei vergleichenden Versuchen mit der Methode von Hoppe-Seyler wird nach der meinigen stets etwas mehr Caseïn erhalten, und zwar um so viel mehr, als nach jener Methode durch Auswaschen des mit Essigsäure erzeugten Niederschlags wieder löslich wird. Aufserdem sind, wie ich gefunden habe, in dem Caseïn nach Hoppe-Seyler stets im Durchschnitt noch 1,8 pC. Asche enthalten, welche man bis jetzt gar nicht berücksichtigt hatte.

In wie weit die neue Art der Bestimmung des Fettes und Caseïns geeignet ist, den analytischen Anforderungen zu entsprechen, wird aus beifolgender Zusammenstellung der Resultate ersichtlich werden, welche ich bei der Untersuchung verschiedener Milchproben sowohl nach meiner, als auch gleichzeitig nach der bis jetzt allgemein üblichen Methode *) erzielt habe.

\section{A. Fettbestimmungen}

\begin{tabular}{|c|c|c|c|}
\hline $\begin{array}{l}\text { in den } \\
\text { Milchproben }\end{array}$ & $\begin{array}{l}\text { nach der gewöhn- } \\
\text { lichen Methode }\end{array}$ & $\begin{array}{l}\text { auf Thonplatten von } \\
\text { geeigneter Porosität }\end{array}$ & Differenz \\
\hline II & $2,97 \mathrm{pC}$ & $3,01 \mathrm{pC}$ & $+0,04$ \\
\hline $\mathrm{II}^{\mathrm{b}}$ & 2,04 & 1,99 & $-0,05$ \\
\hline III & 3,58 & 3,58 & - \\
\hline IIII & 3,30 & 3,26 & $-0,04$. \\
\hline
\end{tabular}

*) Fettbestimmunpen durch Eindampfen der Milch mit Seesand oder Marmorpulver, Trocknen des Rückstandes bei $100^{\circ} \mathrm{C}$. und 6 stündiges Ausziehen desselben mit Aether im Verdrängungsapparat mit Rückflưskühler.

Caseïnbestimmungen durch Ausfällen mit Essigsäure nach Hoppe-Seyler's Vorschrift (Handbuch der physiologisch- und 
der Caseïn- und Fettbestimmung in der Milch. 365

in den nach der gewöhnMilchproben lichen Methode

$\begin{array}{rrr}\text { I } & \mathbf{2 , 9 2} \mathrm{pC} . \\ \text { IV } & 3,10 \\ \text { V } & \mathbf{3 , 2 4} & \\ \text { VI } & \mathbf{3 , 1 0}\end{array}$

auf Thonplatten von

zu grofser Porosität

$$
\begin{aligned}
& 2,28 \mathrm{pC} . \\
& 2,47 \quad \\
& 2,46 \quad \\
& 2,73 \text { " }
\end{aligned}
$$

Differenz

$-0,64$

$-0,63$

$-0,78$

- 0,37.

Beim Vergleich der beiden vorderen Zahlenreihen der ersten Abtheilung wird ersichtlich, dafs die auf zweckentsprechenden Thonplatten erzielten Resultate im Vergleich zu den nach der gewöhnlichen Methode erhaltenen kaum beachtenswerthe Differenzen ergeben. Aber auch diese werden sich (wenn es überhaupt noch nöthig sein sollte) durch weitere Ausbildung meiner Methode vermeiden lassen.

\section{B. Caseinbestimmungen.}

\begin{tabular}{|c|c|c|c|}
\hline $\mathrm{Nr}$ & Hoppe-Seyler & Thonplatten & Differenz \\
\hline $\mathbf{I}$ & 2,85 & 3,11 pC. & $+0,26$ \\
\hline II & 2,52 & 2,93 & $+0,41$ \\
\hline III & 2,42 & 3,04 & $+0,62$ \\
\hline IV & 2,36 & 2,51 & $+0,15$ \\
\hline $\mathbf{V}$ & 2,43 & 2,49 & $+0,06$ \\
\hline VI & 2,24 & 2,53 & $+0,29$ \\
\hline
\end{tabular}

in den Milchproben nach

auf

Demnach wird auf Thonplatten stets eine gröfsere Caseinmenge gefunden, als durch Ausscheidung mit Essigsäure; es fragt sich daher, welche Resultate die richtigeren seien. Um darüber entscheiden zu können schien es mir erforderlich, den Stickstoffgehalt der Trockensubstanz der einzelnen Milchproben und in den letzteren gleichzeitig auch das Albumin und im Filtrat von diesem den restirenden Stickstoff *)

pathologisch-chemischen Analyse von demselben, 4. Aufl., S. 434), jedoch mit dem Unterschiede, dals noch die Asche im Casein bestimmt und in Abrechnung gebracht wurde.

*) Der Stickstoff im Filtrat vom Albumin ist jedenfalls in der Form von Peptonen und in Spuren als Harnstoff, Kreatin, Kreatinin, Leucin und Tyrosin ursprünglich in der Milch enthalten. 
zu bestimmen. Berechnel man nach diesem analytischen Befund das Casein zu 15,7 pC. Stickstoff und das Albumin zu 15,5 pC., addirt die auf diese Weise gefundenen Mengen Stickstoff zu den restirenden, so mufs sich annähernd dieselbe Menge Stickstoff wie bei der directen Bestimmung des gesammten Stickstoffs in der Milch ergeben. Ich habe diefs mit vier der obigen Milchproben durchgeführt :

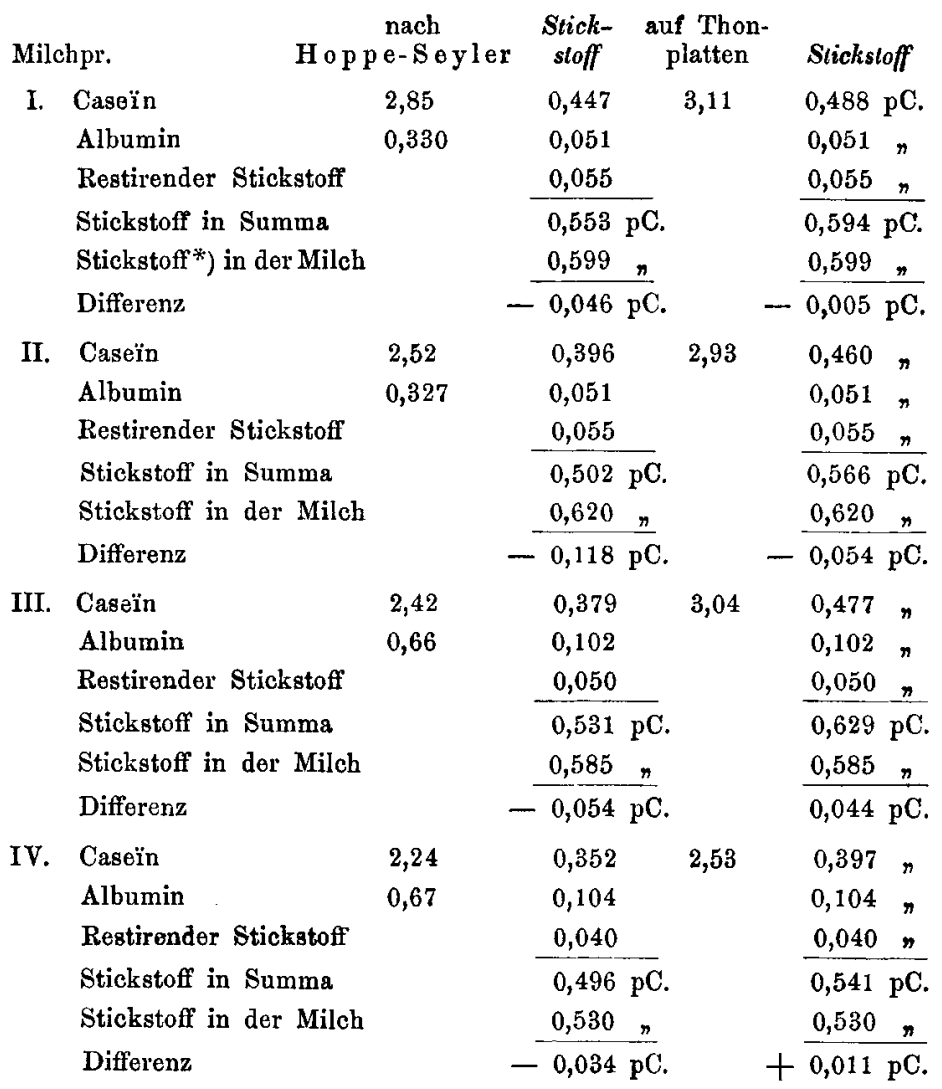

*) Der Stickstoff in der Milch wurde durch Verbrennen der Milchtrockensubstanz mit Natronkalk bestimmt. 
Aus diesem analytischen Befund und den darauf basirten Berechnungen wird ersichtlich, dafs beide Methoden der Caseïnbestimmung ganz befriedigende Resultate ergeben. Denn nach Hoppe-S eyler betragen die Differenzen zwischen dem direct bestimmten und dem durch Berechnung gefundenen Stickstoff 0,034 bis $0,118 \mathrm{pC}$., im Mittel $0,063 \mathrm{pC}$., nach meiner Methode jedoch nur 0,005 bis $0,054 \mathrm{pC}$., im Mittel 0,028 pC. Stickstoff.

Wenn berücksichtigt wird, welcher Zeitaufwand seither nöthig war, um das Casein und Fett in der Milch quantitativ zu bestimmen, so lälst sich annehmen, dafs meine in verbältnifsmäfsig sehr kurzer Zeit auszuführende Methode in physiologischen, agriculturchemischen und sanitätspolizeilichen Laboratorien die allgemeinste Anwendung finden werde.

\section{Anmerkung.}

Sobald zweckentsprechende Thonplatten angefertigt sein werden, soll die Firma, von welcher dieselben, sowie die übrigen, zur genauen Durchführung der neuen Methode nöthigen Geräthschaften bezogen werden können, bekannt gegeben werden.

M ün $\mathrm{ch}$ en, königl. agriculturchemische Centralstation für Bayern. 